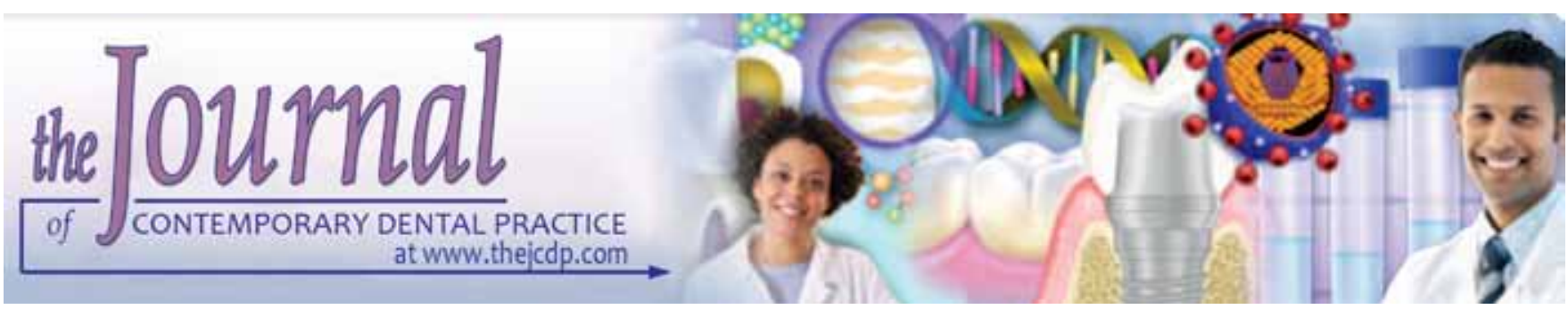

\title{
Effect of Carbamide Peroxide on the Push-out Bond Strength of Different Composition Glass-Ionomer Cement to Root Canal Dentin when used as Cervical Barrier
}

\footnotetext{
${ }^{1}$ Suellen Nogueira Linares Lima, ${ }^{2}$ Ana Carolina Venção, ${ }^{3}$ Milton Carlos Kuga, ${ }^{4}$ Miriam Graziele Magro

${ }^{5}$ Aimeé Maria Guiotti, ${ }^{6}$ José Claudio Martins Segalla, ${ }^{7}$ Keren Crisitina Fagundes Jordão-Basso

${ }^{8}$ Weber Adad Ricci, ${ }^{9}$ Mateus Rodrigues Tonetto, ${ }^{10}$ Matheus Coelho Bandéca
}

\begin{abstract}
Aim: To evaluate the effect of $37 \%$ carbamide peroxide on the bond strength of conventional or resin-modified glass-ionomer cements when used as a cervical barrier in endodonticallytreated teeth.
\end{abstract}

Materials and methods: After root canal instrumentation and obturation, 40 specimens of the cement-enamel junction were obtained after transversal root canal sectioning from human extracted canines. The root canal specimens were standardized and filled with the following materials $(n=10$, each group): $G 1$ : zinc phosphate (control), G2: Ketac glass-ionomer, G3: vitrebond glass-ionomer or G4: GC GL glass-ionomer. After 24 hours, the specimens were subjected to an application of $37 \%$ carbamide peroxide for 21 days, changed each 7 days and stored in an artificial pulp chamber. The specimens were then submitted to push-out bond strength testing with an electromechanical test machine (EMIC) and the failure mode in each specimen was analyzed with confocal microscopy (LEXT).

Results: G3 and G4 showed higher bond strengths values than the other groups $(p<0.05)$, and were similar to each other $(p>0.05)$. G1 showed the lowest bond strength value $(p<0.05)$

\footnotetext{
${ }^{1,10}$ Department of Postgraduate Program in Dentistry, School of Dentistry, CEUMA University, São Luis, MA, Brazil

2-4,6-8 Department of Restorative Dentistry, School of Dentistry Univ Estadual Paulista, Araraquara, São Paulo, Brazil

${ }^{5}$ Department of Dentistry, School of Dentistry, Univ Estadual Paulista, Araçatuba, São Paulo, Brazil

${ }^{9}$ Department of Postgraduate Program in Integrated Dental Science, School of Dentistry, University of Cuiabá-UNIC, Cuiabá MT, Brazil

Corresponding Author: Matheus Coelho Bandéca, Professor Department of Postgraduate Program in Dentistry, Rua Jossue Montello, 01, Renascença, CEP 65075-120, São Luís, MA Brazil, e-mail: mbandeca@gmail.com
}

Conclusion: Glass-ionomer cements showed higher bond strength values than the zinc phosphate cement, and resinmodified glass-ionomer cements presented the highest push-out values to root canal dentin (GC, GL and Vitrebond).

Clinical significance: Glass ionomer cements are recommended to use as cervical barrier materials before the internal dental bleaching, but its efficiency is questionable.

Keywords: Bleaching agents, Carbamide peroxide, Dentinbonding agents, Endodontic, Glass ionomer cements.

Howtocitethis article:LimaSNL, VençãoAC,KugaMC,MagroMG, Guiotti AM, Segalla JCM, Jordão-Basso KCF, Ricci WA, Tonetto MR, Bandéca MC. Effect of Carbamide Peroxide on the Push-out Bond Strength of Different Composition Glass-Ionomer Cement to Root Canal Dentin when used as Cervical Barrier. J Contemp Dent Pract 2015;16(12):944-949.

Source of support: Nil

Conflict of interest: None declared

\section{INTRODUCTION}

The cervical barrier is a protection procedure performed between the root canal obturation and the pulp chamber before internal bleaching in order to hinder the peroxides diffusion in the radicular apical and extra-radicular directions. Several restorative materials, endodontic sealers, bioceramic or calcium silicate-based materials were recommended to this objective. ${ }^{1}$

These materials should present satisfactory adhesion to the radicular dentin and not degrade after the internal dental bleaching procedures, mainly after the use of hydrogen peroxide and its derivatives. ${ }^{1}$ The glassionomer cements are the most recommended material to be used as cervical barrier due to its adhesion properties to enamel and dentin, thermal expansion coefficient similar to tooth structure and fluoride release. ${ }^{2,3}$ However, its efficacy has only been evaluated by leakage tests. ${ }^{4}$ 
Despite its recognized properties, the conventionalglass ionomer cements have some disadvantages, such as lack of sufficient mechanical strength and toughness. ${ }^{3,5}$ These cements are mechanically poor due to the weak bonding between the glass particles and the polyacid matrix, and the same does not occur in the composites due to the presence of the silane. ${ }^{6}$ In order to improve these mechanical properties, the resin-modified glass-ionomer cement containing hydrophilic monomers and polymers like HEMA was developed with higher adhesion to the tooth structure. ${ }^{3,7,8}$ This property is owed to the increase of the material cohesive strength to the dentin. ${ }^{9}$

In vital dental bleaching using hydrogen peroxide does not increase significant deleterious effects on the glass-ionomer cement structure, but the full maturity stage of the aluminum matrix polycarboxylate formation must be completed, especially for the conventional glass ionomer, which can take from 24 to 48 hours to be accomplished. ${ }^{10,11}$

However, in vital dental bleaching the contact time of the hydrogen peroxide with the glass-ionomer cement are short and predetermined, unlike the internal bleaching protocols, where the hydrogen peroxide remains during the whole treatment. ${ }^{12-14}$ On the other hand, there are no studies evaluating the effects of hydrogen or carbamide peroxide on adhesion from conventional or resinmodified glass-ionomer cements in radicular dentin, when used as a cervical barrier.

The aim of this study was to evaluate the push-out bond strength of a conventional glass-ionomer cement (Ketac) and two resin-modified glass-ionomers (GC Gold Label and Vitrebond) in the cervical dentin, when used as cervical barrier material after internal dental bleaching using $37 \%$ carbamide peroxide.

\section{MATERIALS AND METHODS}

Human maxillary canines extracted for periodontal disease were selected for this study. After cleaning, the external root surfaces were radiographed from the mesiodistal and buccolingual directions and 40 teeth with similar root canal anatomy were selected. The teeth were stored in $1 \%$ thymol solution at $4^{\circ} \mathrm{C}$. The cavity accesses were prepared and the working length was determined by the insertion of a \# $15 \mathrm{~K}$-file into the root canal until the end of the file was visible at the apex. One millimeter was subtracted from this measure and defined as the instrumentation length. Initially, \# 3 and \# 4 Gates Glidden drills (Maillefer, Ballaigues, Switzerland) were used to flare the coronal third root. The root canals were instrumented with a ProTaper Rotary System (Dentsply-Maillefer, Ballaigues, Switzerland) until the F5 instrument, according to the manufacturer's instructions.
The canals were irrigated with $5 \mathrm{ml}$ of $2.5 \% \mathrm{NaOCl}$ in each instrument change. As a final irrigation, the root canals were irrigated with $5 \mathrm{ml}$ of $17 \%$ EDTA (Biodynamics, Londrina, PR, Brazil) and kept in the root canal for 3 minutes and again irrigated with $5 \mathrm{ml}$ of $2.5 \%$ $\mathrm{NaOCl}$. The root canals were immediately dried with paper points and filled with an epoxy-based sealer $\mathrm{AH}$ Plus; Dentsply DeTrey GmbH, Konstanz, Germany) and a F5 gutta-percha point by single cone technique. The guttapercha was cut at the tooth cervical level and the cavity access were restored with provisional cement (Coltosol; Coltene, Rio de Janeiro, RJ, Brazil). The teeth were stored in artificial saliva (Farmácia Ação, Araraquara, São Paulo, Brazil) for 7 days at $37^{\circ} \mathrm{C}$.

The dental crowns were then removed with a doublesided diamond disk, $1 \mathrm{~mm}$ below the cementoenamel junction, under distilled water irrigation. The roots were placed inside a plastic matrix $(20 \mathrm{~mm}$ length $\times 16.7 \mathrm{~mm}$ internal diameter) and the cervical face was positioned $1 \mathrm{~mm}$ below the plastic matrix external surface and embedded in polyester resin (Maxi Rubber, Diadema, São Paulo, Brazil). All specimens remained intact for 24 hours. After resin polymerization, the samples were ground using silicon carbide papers (Norton, Lorena, São Paulo, Brazil) with \# 600 abrasiveness with a polishing machine (AROTEC, Cotia, São Paulo, Brazil) until exposure of the root cervical face. Forty slices with $2 \mathrm{~mm}$ thickness at the cementoenamel junction were obtained transversely of each root with a slow-speed diamond saw (Isomet; Buehler Ltd., Lake Bluff, IL, USA).

The root canal diameter of each slice was standardized using a low-speed handpiece and a \#703 steel conical bur (Vortex, Prod. Dentistry, São Paulo, Brazil) attached to the arm of the surveyor 12 . The root canal diameters were standardized as: larger diameter $=1.65 \mathrm{~mm}$, smaller diameter $=1.40 \mathrm{~mm}$. The specimen preparation was carried out under distilled water irrigation. After this step, all specimens were observed with a stereomicroscope (S8APO; Leica Microsystems, Wetzlar, Germany) at 20x magnification to assess their integrity and the quality of the preparation.

The specimens were randomly divided in 4 groups ( $\mathrm{n}=10$, each group), according to the used material: G1: (control), zinc phosphate cement (SS White, Rio de Janeiro, Brazil), the material was handled and immediately inserted into the root canal of the prepared specimen; G2: (Ketac Molar), the dentin was previously conditioned with polyacrylic acid for 10 seconds and irrigated with $5 \mathrm{ml}$ of distilled water. In sequence, the glass-ionomer cement was handled and inserted into the root canal; G3: (Vitrebond), the cement was handled and immediately inserted into the root canal 
and light cured with a LED system (Ultra Blue IS 600, DMC, São Carlos, São Paulo, Brazil) for 30 seconds; G4: (GC Light-cured Gold Label Universal Restorative), etching agent (GC Dentin Conditioner; GC Corporation, Tokyo, Japan) was applied for 20 seconds on the dentin, washed with distilled water and dried with air and, in sequence glass-ionomer cement was inserted into the root canal and light cured for 20 seconds, as described for G3. All materials were handled according to the manufacturers' recommendations. Table 1 shows the compositions of the used in present study.

After the preparation filling, the cements were protected with propylene glycol gel (KY, Johnson and Johnson, São Paulo, Brazil) and stored at $37^{\circ} \mathrm{C}$ and $95 \%$ humidity for 24 hours. Next, the specimens were individually placed into a metal device $(10 \mathrm{~mm}$ length $x$ $16.7 \mathrm{~mm}$ internal diameter) and $37 \%$ carbamide peroxide was applied over the coronal face of each specimen (Whiteness Superendo; FGM Produtos Odontológicos, Joinville, SC, Brazil) for 21 days and replaced each 7 days. The metal devices were kept closed at $37^{\circ} \mathrm{C}$ during all experiment. Figures $1 \mathrm{~A}$ to D shows the specimen preparation sequence.

After this period, the slices were washed and ground smooth using \#600 silicon carbide papers (Norton, Lorena, São Paulo, Brazil) and fixed to the metallic apparatus so that the side with the smaller diameter of the root canal faced upwards. The tip of the plunger used for load application in the push-out test had a diameter of $1.3 \mathrm{~mm}$ and was aligned perpendicularly to the upper

Table 1: Chemical composition, manufacturer and origin of cements used as a cervical barrier

\begin{tabular}{lll}
\hline Cement & Composition & Manufacture \\
\hline Zinc phosphate & $\begin{array}{l}\text { Powder-zinc oxide, magnesium oxide, pigments } \\
\text { Liquid-phosphoric acid, aluminum hydroxide, zinc oxide, distilled water }\end{array}$ & SS White, Rio de Janeiro, \\
Ketac molar easymix & $\begin{array}{l}\text { Powder-Al-Ca-La fluorosilicate glass, polyacrylic acid, eudragit, tartaric } \\
\text { acid, sorbic acid, benzoic acid and pigments } \\
\text { Liquid-water, polyacrylic acid maleic acid, tartaric acid, and benzoic acid }\end{array}$ & $\begin{array}{l}\text { 3M Espe AG, Seefeld, } \\
\text { Germany }\end{array}$ \\
Vitrebond & $\begin{array}{l}\text { Powder-fluoro-aluminosilicate glass } \\
\text { Liquid-polyalkenoic acid }\end{array}$ & 3M Espe, St Paul, MN, USA \\
GC GL Light-cured & $\begin{array}{l}\text { Powder-Alumino-fluoro-silicate glass (amorphus) } \\
\text { Lniversal restorative } \\
\text { Liquid-Polyacrylic acid, 2-Hydroxyethyl methacrylate, 2.2.4 Trimethyl } \\
\text { hexamethylene dicarbonate, Triethylene glycol dimethacrylate. }\end{array}$ & $\begin{array}{l}\text { GC, Itabashi-ku, Tokyo, } \\
\text { Japan }\end{array}$ \\
\hline
\end{tabular}
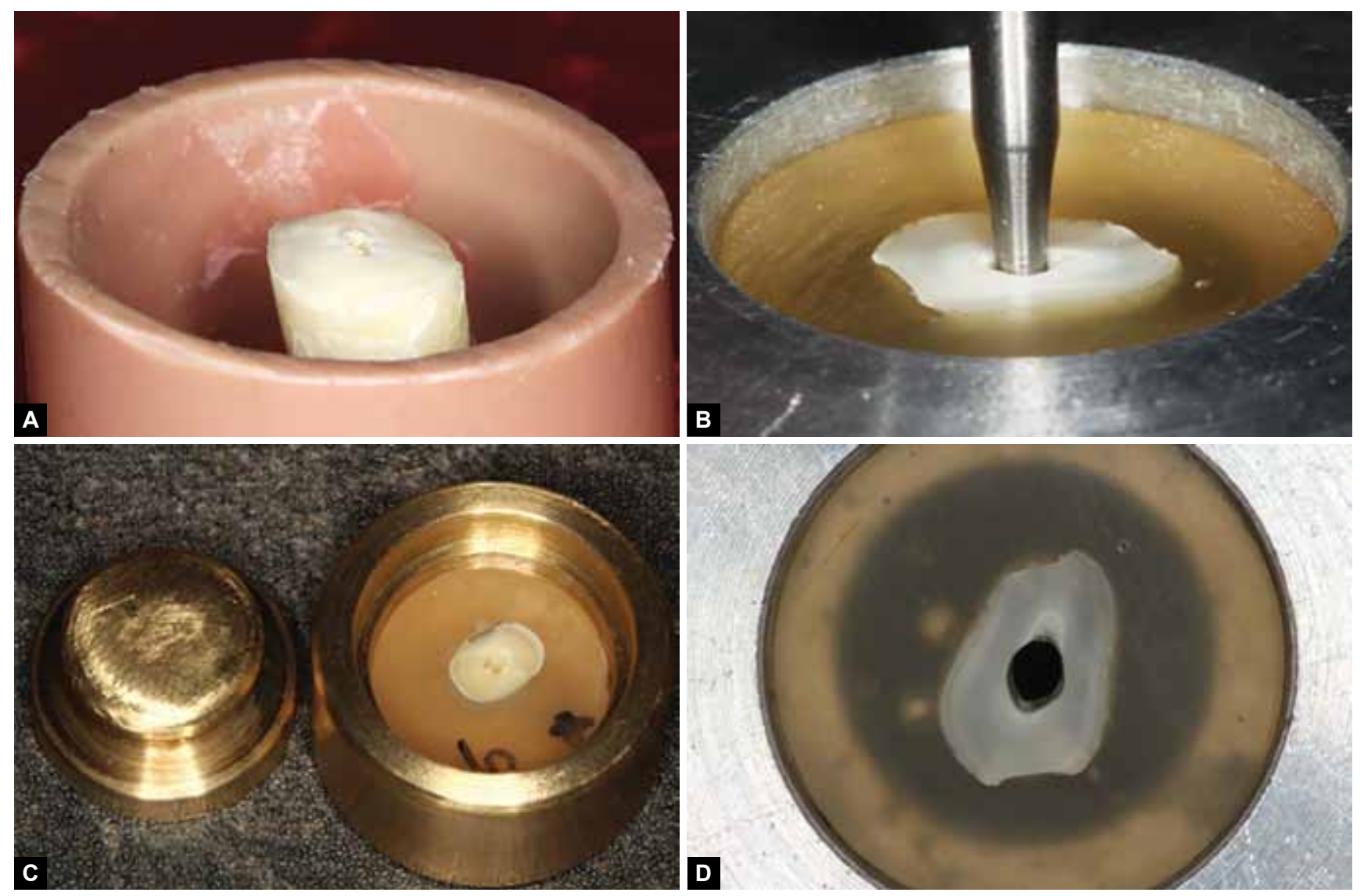

Figs 1A to D: Sequence of specimen preparation for the push-out bond strength test: (A) tooth resin inclusion, (B) preparation of the cervical barrier, $(C)$ root canal preparation and (D) the specimen device to receive the bleaching agent ( $37 \%$ carbamide peroxide) 
face of the slice. The push-out test was performed using an electromechanical testing machine (EMIC DL; Emic, São José dos Pinhais, PR, Brazil), calibrated at a constant speed of $0.5 \mathrm{~mm} / \mathrm{min}$. The cervical barrier was subjected to axial force until it was dislodged from the root canal section. The force needed to dislodge the filling materials $(\mathrm{kN})$ was transformed into tension megapascal (MPa). ${ }^{15}$

The results obtained for each group were subjected to the ANOVA and Tukey tests ( $p=0.05)$ using the Graph Pad Prism 5.01 statistical software (Graph Pad Software, San Diego, CA). After the push-out test, each specimen was examined under a confocal laser scanning microscope LEXT OLS4100; Olympus, Shinjuku-ku, Tokyo, JP) at 50× magnification to determine the failure mode. Failure mode was classified as: adhesive, when occurring along the sealer/dentin interface; cohesive, within the filling material; and mixed, when both types of failure were combined. After confocal microscopic analysis of each specimen, the frequency of failure mode was obtained to the control group and to conventional or resin-modified glass-ionomer cements groups.

\section{RESULTS}

The means and standard deviations $\mathrm{MPa}$ of the push-out bond strength of different groups to the dentin were: G1 $(0.210 \pm 0.090), G 2(1.276 \pm 0.363), G 3(3.370 \pm 0.940)$ and G4 (4.182 \pm 1.072$)$. G1 showed the lowest push-out bond strength values to the dentin than all the other groups ( $p<0.05)$. G3 and G4 showed the highest push-out bond strength values to the dentin $(p<0.05)$ and were similar each other ( $p>0.05)$. G2 showed higher push-out bond strength to the dentin than G1 ( $\mathrm{p}<0.05)$.

Regarding the failure mode, G3 and G4 presented only cohesive failure, G2 showed higher incidence of mixed failure. In contrast, G1 showed higher incidence of adhesive failure. Table 2 presents the incidence of failure mode for each group. Figures $2 \mathrm{~A}$ to $\mathrm{C}$ showed the adhesive, mixed and cohesive failure mode obtained by surface confocal laser microscopy.
Table 2: Failure mode incidence after the push-out test for each group

\begin{tabular}{lllll}
\hline & G1 & G2 & G3 & G4 \\
\hline Adhesive & 7 & 0 & 0 & 0 \\
Mixed & 2 & 6 & 0 & 0 \\
Cohesive & 1 & 4 & 10 & 10 \\
\hline
\end{tabular}

G1: Zinc phosphate cement; G2: Ketac Molar Easymix; G3:

Vitrebond; G4: GC GL Light-cured universal restorative

\section{DISCUSSION}

The cervical barrier with zinc phosphate cement (control group) showed lower push-out bond strength to the dentin, after the application of $37 \%$ carbamide peroxide, than all the glass-ionomer cements. Under similar conditions, the resin-modified glass ionomer cements (GC Gold Label and Vitrebond) presented higher bond strength to the dentin than the conventional glass ionomer cement (Ketac).

These results are according with studies in conventional restauration which showed that the push-out bond strength of the glass-ionomer cements to the dentin is from 1.1 to $4.5 \mathrm{MPa}$, but dependent of previous dentin substrate treatment with polyacrylic acid and/or the chemical composition of the glass-ionomer cement, such as in resin-modified glass-ionomer cements. ${ }^{9,16-18}$

The different chemical compositions interfered on the push-out bond strength results of the glass-ionomer cements to the dentin after the $37 \%$ carbamide peroxide internal bleaching protocol. Resin-modified glassionomer cement consist mainly of glass-ionomer and a minor amount of resin and has shown higher adhesion to the dentin than conventional glass-ionomer cement. ${ }^{19}$

This is related to the adhesion mechanism of these materials, because the conventional glass-ionomer cement adhesion is a dynamic process of ions exchange in the polyalkenoic acid which softens and infiltrate in the hydroxyapatite structure, displacing calcium and phosphate ions from the substrate. As consequence, an intermediate layer made of calcium, aluminum
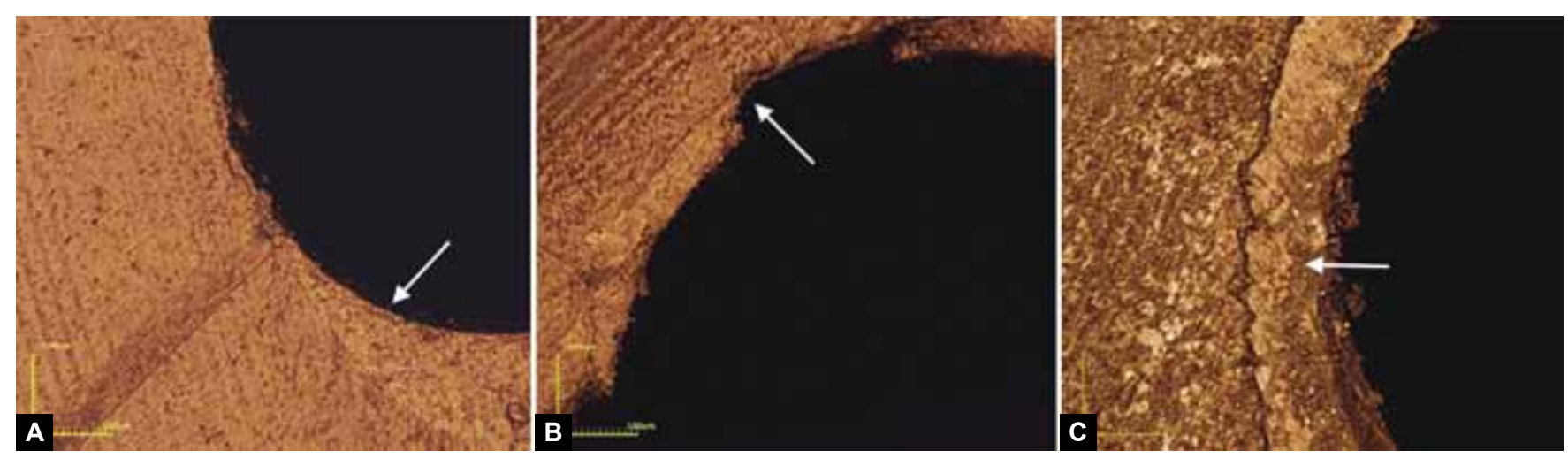

Figs 2A to C: Failure mode images obtained by confocal microscopy: $(A)$ adhesive, $(B)$ mixed and $(C)$ cohesive. The white arrow shows presence or absence of the cement 
phosphates and polyacrylates is formed at the glassionomer-hydroxyapatite interface..$^{20-22}$

On the other hand, the resin-modified glass-ionomer cement adhesion to the substrate also occurs by a micromechanical bonding mechanism, similar to dentin adhesive systems. ${ }^{23,24}$ The acid from the resin monomers promotes the formation of resin tags within the dentinal tubules due to the tooth surface demineralization. ${ }^{21}$

It is possible that the water-soluble gel used for the cervical barrier protection may have favored the specimen hydration, mainly to the resin-modified glass-ionomer cements, since the glass ionomer cements promote setting shrinkage stress causing fractures that compromise the adhesion integrity of the material and the dentin interface. ${ }^{25,26}$ This protection also avoided any contamination at the initial stage of the setting reaction, preventing absorption and consequently the dissolution of a formed matrix that could compromise the cements marginal integrity and mechanical properties. ${ }^{27}$ Additionally, has been observed that the resin-modified glass-ionomer cements presented higher potential for closure of cracks than the conventional glass-ionomer cement after hydration. ${ }^{28}$

The $37 \%$ carbamide peroxide was the chosen bleaching material due to its clinical safety, since it shows lower radicular penetration than hydrogen peroxide..$^{29}$ The application time and the type of material used in tooth bleaching can promote the glass-ionomer cement disintegration, increasing its surface roughness, but did not interfere in microhardness, regardless of their chemical composition. ${ }^{10,30-32}$ However, after 21 days of application of $37 \%$ carbamide peroxide, the push-out bond strength of the resin-modified glass-ionomer cement to cervical dentin was higher than the conventional glass-ionomer cement, as observed for conventional restorations. ${ }^{19,21,33}$

Regarding the failure mode, G1 presented high incidence of adhesive failures because the zinc phosphate cement has high solubility and the adhesion only occurs by mechanical interaction at the interface, without chemical interactions. ${ }^{1}$ On the other hand, G3 and G4 did not presented adhesive failures, only cohesive, and showed higher values to the push-out bond strength of resin-modified glass-ionomer cements to the substrate, possibly due to its mechanism of adhesion to the dentin. ${ }^{21}$ G2 showed mixed and cohesive failures, probably due to the absence of resin in its composition. .1,34 $^{2}$

This new methodology evaluated the action of $37 \%$ carbamide peroxide on different glass-ionomer cement compositions in similar conditions to the pulp chamber, under constant chemical action. The material evaluated by the push-out test and failure mode analysis can assess the dental bleaching materials effects on the cervical barrier with accuracy, in comparison to infiltration methods. ${ }^{4,29,35,36}$

The cervical barrier using glass-ionomer cements may have different results depending on the bleaching agent chemical composition and/or application time at the cervical barrier of endodontically-treated teeth. However, future studies using the described methodology are needed to evaluate the best material for use as a cervical barrier in endodontically-treated teeth bleaching.

\section{CONCLUSION}

Therefore, glass-ionomer cement used as a cervical barrier showed higher push-out bond strength values than the zinc phosphate cement. The highest values were for the resin-modified glass-ionomer cements (GC Light-cured Gold Label Universal Restorative and Vitrebond) after an internal dental bleaching protocol using $37 \%$ carbamide peroxide.

\section{CLINICAL SIGNIFICANCE}

Glass ionomer cements are recommended to use as cervical barrier materials before the internal dental bleaching, but its efficiency is questionable.

\section{ACKNOWLEDGMENTS}

The authors would like to thank CAPES, FAPEMA and UniCEUMA for their financial support.

\section{REFERENCES}

1. Plotino G, Buono L, Grande NM, Pameijer $\mathrm{CH}$, Somma F. Nonvital tooth bleaching: a review of the literature and clinical procedures. J Endod 2008 Apr; 34(4):394-407.

2. Rotstein I, Zyskind D, Lewinstein I, Bamberger N. Effect of different protective base materials on hydrogen peroxide leakage during intracoronal bleaching in vitro. J Endod 1992 Mar;18(3):114-117.

3. Khoroushi M, Keshani F. A review of glass-ionomers: from conventional glass-ionomer to bioactive glass-ionomer. Dent Res J 2013 Jul;10(4):411-420.

4. Madhu KS, Hegde S, Mathew S, Lata DA, Bhandi SH, Shruthi N. Comparison of radicular peroxide leakage from four commonly used bleaching agents following Intracoronal bleaching in endodontically treated teeth: an in vitro study. J Int Oral Health 2013 Aug;5(4):49-55.

5. Yip HK, Smales RJ. Glass ionomer cements used as fissure sealants with the atraumatic restorative treatment approach: review of literature. Int Dent J 2002 Apr;52(2):67-70.

6. McLean JW, Wilson AD. Glass-ionomer cements. Br Dent J 2004 May 8;196(9):514-515.

7. Yli-Urpo H, Lassila LV, Närhi T, Vallittu PK. Compressive strength and surface characterization of glass ionomer cements modified by particles of bioactive glass. Dent Mater 2005 Mar;21(3):201-209. 
8. Hübel S, Mejàre I. Conventional versus resin-modified glassionomer cement for class II restorations in primary molars. A 3-year clinical study. Int J Paediatr Dent 2003 Jan;13(1):2-8.

9. Li J, Liu Y, Liu Y, Söremark R, Sundström F. Flexure strength of resin-modified glass ionomer cements and their bond strength to dental composites. Acta Odontol Scand 1996 Feb; 54(1):55-58

10. Campos I, Briso AL, Pimenta LA, Ambrosano G. Effects of bleaching with carbamide peroxide gels on microhardness of restoration materials. J Esthet Restor Dent 2003;15(3):175-182.

11. Banomyong D, Palamara JEA, Burrow MF, Messer HH. Effect of dentin conditioning on dentin permeability and microshear bond strength. Eur J Oral Sci 2007 Dec;115(6):502-509.

12. Özkan P, Kansu G, Özak ST, Kurtulmuş-Yilmaz S, Kansu P. Effect of bleaching agents and whitening dentifrices on the surface roughness of human teeth enamel. Acta Odontol Scand 2013 May-Jul;71(3-4):488-497.

13. Kuga MC, dos Santos Nunes Reis JM, Fabrício S, BonettiFilho I, de Campos EA, Faria G. Fracture strength of incisor crowns after intracoronal bleaching with sodium percarbonate. Dent Traumatol 2012 Jun;28(3):238-242.

14. Leonardo Rde T, Kuga MC, Guiotti FA, Andolfatto C, FariaJúnior NB, Campos EA, Keine KC, Dantas AA. Fracture resistance of teeth submitted to several internal bleaching protocols. J Contemp Dent Pract 2014 Mar 1;(15)2:186-189.

15. Guiotti FA, Kuga MC, Duarte MA, Sant'Anna AJ, Faria G. Effect of calcium hydroxide dressing on push-out bond strength of endodontic sealers to root canal dentin. Braz Oral Res 2014 Jan-Feb;28(1).

16. Powis DR, FollerasT, Merson AS, Wilson AD. Improved adhesion of a glass-ionomer cement to dentin and enamel. J Dent Res 1982 Dec;61(12):1416-1422.

17. Attin $T$, Buchalla $W$, Hellwig E. Influence enamel conditioning on bond strength of resin-modified glass-ionomer restorative materials and polyacid-modified composites. J Prosthet Dent 1996 Jul;76(1):29-33.

18. Frtiz UB, Finger WJ, Uno S. Resin-modified glass-ionomer cements: bonding to enamel and dentin. Dent Mater 1996 May;12(3):161-166.

19. Rekha CV, Varma B, Jayanthi. Comparative evaluation of tensile bond strength and microleakage of conventional glass ionomer cement, resin modified glass ionomer cement and compomer: an in vitro study. Contemp Clin Dent 2012 Jul; 3(3):282-287.

20. Wilson AD, Prosser HJ, Powis DM. Mechanism of adhesion of polyelectrolyte cements to hydroxyapatite. J Dent Res 1983 May;62(5):590-592.

21. Lin A, McIntyre NS, Davidson RD. Studies on the adhesion of glass-ionomer cements to dentin. J Dent Res 1992 Nov; 71(11): 1836-1841.

22. Mount GJ. Glass-ionomer cements: past, present and future. Oper Dent 1994 May-Jun;19(3):82-90.
23. Maneenut C, Tyas MJ. Clinical evaluation of resin-modified glass-ionomer restorative cements in cervical 'abrasion' lesions: one-year results. Quintessence Int 1995 Oct;26(10): 739-743.

24. Gladys S, Van Meerbeek B, Lambrechts P, Vanherle G. Marginal adaptation and retention of a glass-ionomer, resinmodified glass-ionomers and a polyacid-modified resin composite in cervical class-V lesions. Dent Mater $1998 \mathrm{Jul}$; 14(4):294-306.

25. Feilzer AJ, Kakaboura AI, de Gee AJ, Davidson CL. The influence of water sorption on the development of setting shrinkage stress in traditional and resin-modified glassionomer cements. Dent Mater 1995 May;11(3):186-190.

26. Tay FR, Sidhu SK, Watson TF, Pashley DH. Water-dependent interfacial transition zone in resin-modified glass-ionomer cement/dentin interfaces. J Dent Res 2004 Aug;83(8):644-649.

27. Shydu SK, Sheriff M, Watson TF. The effects of maturity and dehydration shrinkage on resin-modified glass-ionomer restorations. J Dent Res 1997 Aug 76(8):1495-1501.

28. Sidhu SK, Pilecki P, Sherriff M, Watson TF. Crack closure on rehydration of glass-ionomer materials. Eur J Oral Sci 2004 Oct;112(5):465-409.

29. Gökay O, Ziraman F, Cali Asal A, Saka OM. Radicular peroxide penetration from carbamide peroxide gels during intracoronal bleaching. Int Endod J 2008 Jul;41(7):556-560.

30. Baroudi K, Mahmoud RS, Tarakji B, Altamimi MA. Effect of vital bleaching on disintegration tendency of glass ionomer restorations. J Clin Diagn Res 2014 Feb;8(2):214-217.

31. Zavanelli AC, Mazaro VQ, Silva CR, Zavanelli RA, Mancuso DN. Surface roughness analysis of four restorative materials exposed to $10 \%$ and $15 \%$ carbamide peroxide. Int J Prosthodont 2011 Mar-Apr;24(2):155-157.

32. Mujdeci A, Gokay O. Effect of bleaching agents on the microhardness of tooth-colored restorative materials. J Prosthet Dent 2006 Apr;95(4):286-289.

33. Sampaio PC, de Almeida Júnior AA, Francisconi LF, Casas-Apayco LC, Pereira JC, Wang L, Atta MT. Effect of conventional and resin-modified glass-ionomer liner on dentin adhesive interface of class I cavity walls after thermocycling. Oper Dent 2011 Jul-Aug;36(4):403-412.

34. Naasan MA, Watson TF. Conventional glass ionomers as posterior restorations: a status report for the American Journal of Dentistry. Am J Dent 1998 Feb;11(1):36-45.

35. Canoglu E, Gulsahi K, Sahin C, Altundasar E, Cehreli ZC. Effect of bleaching agents on sealing properties of different intraorifice barriers and root filling materials. Med Oral Patol Oral Cir Bucal 2012 Jul;17(4):e710-715.

36. Vosoughhosseini S, Lotfi M, Shahmoradi K, Saghiri MA, Zand V, Mehdipour M, et al. Microleakage comparison of glass-ionomer and white mineral trioxide aggregate used as a coronal barrier in nonvital bleaching. Med Oral Patol Oral Cir Bucal 2011 Nov;16(7):e1017-1021. 